$M$ en's sexual health is a hot topic. There is now a men's health forum with its own parliamentary group, and an increasing profile for men's health in the press. Although men are often underrepresented in healthcare use, this is not the case in genitourinary medicine (GUM) services. In 2003, 47\% of the 608636 total diagnoses recorded in England were for men. GUM services have provided services for gay men for many decades and, given the HIV epidemic, are clearly important in diagnosing HIV infection, and, in collaboration with others, managing those found to be infected. In contrast, research into heterosexual men's sexual health has only recently become prominent. Men are often perceived as having less interest than women in taking care of their own health, and in general use services less. Compared with other outpatient services, GUM clinics must have one of the highest numbers of young males attending. This is encouraging because, from the point of view of transmission of sexually transmitted infections and pregnancy, men are at least half the equation and certainly half of the solution. The recent introduction of technologies allowing diagnosis using non-invasive specimens has permitted novel ways to be explored in screening for sexually transmitted infections.

Following the successful themed issue of Sexually Transmitted Infections on adolescent sexual health in 2001, an issue devoted to men seemed highly appropriate. This themed edition on men's sexual health was proposed by the British Association for Sexual Health and HIV (BASSH). The editors were enthusiastic, and the call has attracted an excellent response. It is particularly gratifying to see the international nature of the contributions. The result is a testament to their efforts and to the hard work of Dr David Lewis, the guest editor for this issue, who took the lead on young men's issues while a member of the BASSH adolescent special interest group. The new information contained within these pages will hopefully stimulate further research on the socio-behavioural issues that influence men's sexual health, epidemiological trends, and diagnoses and management of sexually transmitted infections in men.

Correspondence to: Dr A J Robinson, Mortimer Market Centre, Capper Street, London WC1E 6AU; arobinson@gum.ucl.ac.uk
Editorial

\section{Improving men's sexual health: a challenge for today}

\section{A Lewis}

\section{Assistant editor Dr David Lewis introduces this special themed issue of the journal}

7 m his special issue of Sexually Transmitted Infections, which addresses men's sexual health, contains contributions from every continent of the world and has proved very popular. Among the issue's themes are sexual behaviour of men having sex with other men (MSM), sexual health services for young men, reasons underlying non-use of condoms, and male commercial sex work. All of these are important facets of men's sexual health. This editorial seeks to highlight some of the main observations and findings relating to these themes from among the published contributions.

Before these are addressed, it is perhaps worth highlighting a few important issues that should be considered by everyone working in the field of men's sexual health. These include the need to acknowledge and understand men's macho attitudes and masculinity, men's concerns over clinic confidentiality and mistrust of professionals, men's perceptions as to whether specific sexual health services are for them or more geared towards women, misinformation about services from peers, and the fact that men's healthcare seeking behaviour often differs from that of women. ${ }^{1}$ In addition, projected staff attitudes towards men may be less than ideal in terms of dealing with boisterous young men presenting in groups, acceptability of MSM sexual behaviour, and the outward presentation of the stereotypical image of men as "the problem" behind spiralling increases in STIs [see page 484 ]. $^{2}$

\section{RISING STI AND HIV INFECTION RATES IN MSM}

Rates of diagnosis of HIV and STIs have increased substantially in MSM in
England and Wales, particularly in London, and reflect increases in high risk sexual behaviour documented in several behavioural surveillance programmes [see page 492]. ${ }^{3}{ }^{4}$ Higher risk sexual behaviour among MSM appears to be associated with low density social networks, the presence of HIV seropositive people within the network, unprotected anal intercourse with casual partners, previous injectable drug use, Black ethnicity, and a belief of low vulnerability to HIV infection, particularly among "active" MSM [see pages 443-465]. ${ }^{5-8}$ These findings demonstrate the importance of understanding the sexual networks of our patients in making an HIV risk assessment and highlight the need to target prevention funding appropriately.

High incidence rates of HIV infection in MSM continue to occur in many countries where highly active anti-retroviral therapy (HAART) is available. The negotiation of risk by HIV seropositive MSM may be less influenced by HIV treatment related beliefs and more by similar serostatus of their sexual partner, fatigue with the "safer sex" message, and the use of recreational drugs [see page 518]. ${ }^{9}$ The reasons underlying the choice of some MSM not to disclose their HIV status to sex partners are complex. Disclosure may be influenced by an individual's level of adjustment to an HIV diagnosis, a sense of responsibility 
to protect partners from infection, and the perception of HIV transmission risks related to various sexual practices in the era of HAART [see page 512]. ${ }^{10}$ Sexual risk reduction counselling of HIV seropositive MSM is often inadequately undertaken by healthcare providers. With the continued increase in HIV infected individuals, the rising rates of STIs amongst MSM, and the increasing pressures on staff time, this important aspect of public health should not be ignored.

\section{SCREENING YOUNG MEN FOR STIS}

A key challenge for sexual health services is to increase the number of young men attending for STI screening. This is important, given that young people bear a disproportionate burden of acute STIs across the world. In 2002, 16-24 year old men accounted for 53\% of all male Chlamydia, $40 \%$ of gonorrhoea, and $43 \%$ of genital warts diagnosed in genitourinary medicine (GUM) clinics in England, Wales, and Northern Ireland. ${ }^{11}$ The English National Strategy for Sexual Health and HIV has specifically identified young men as a priority group for interventions and research. ${ }^{12}$

There exists a debate over the relative merits of young people centred services (often favoured by young people themselves) and dedicated youth services (often advocated by healthcare professionals). Certainly, dedicated youth services tend to have limited opening hours and are not widely available. However, it is difficult to transform mainstream sexual health services into young people centred services without alienating many older patients. It may take several years for young men to attend dedicated young people's services in large numbers, which makes it important to convince funding agencies to persevere with such projects [see page 477]. ${ }^{13}$ Ensuring that staff adequately understand young men's behaviour and are young men "friendly" is crucial to service success, and the role of staff training and feedback cannot be overemphasised. ${ }^{2}$ There may be a place for young men-only services in locations with high STI prevalence rates. Experience in southeast London demonstrated that a service directed specifically at young men's needs did encourage health seeking behaviour among friends of service users as well as detect a significant number of STIs [see page 480]. ${ }^{14}$

\section{CONDOM USE}

Improved condom use by men would clearly help reduce both STIs and unwanted pregnancies. The psychological and physical processes underlying men's decisions not to use condoms are complex. Personal factors often appear to be the most important determinants of non-use of condoms, which suggests that direct interventional approaches and peer education may be justified with vulnerable high risk groups [see pages 425 and 435]. ${ }^{15}$ Some men, however, choose not to use condoms simply because they make sexual intercourse unpleasurable [see page 430]. ${ }^{17}$ Given these observations, it is important that condom promotion campaigns carry the correct messages for their target population. It is vital that such prevention work is continued to be supported because it is unlikely that strategies based on abstinence will be successful in stemming the HIV/AIDS epidemic worldwide.

\section{COMMERCIAL SEX WORK}

Finally, this special edition contains a number of papers addressing male commercial sex work. Men may engage in sex work for a number of reasons: sex may be exchanged for gifts, drugs, shelter, as well as money, and this behaviour provides a survival mechanism for some young men in large cities [see page 526]..$^{18}$ Males involved in the sex trade do appear to be at higher risk for HIV infection and often engage in other high risk behaviours, such as injectable drug use [see pages 526 and 531]. ${ }^{1819}$ Transgender sex workers appear to be particularly vulnerable to HIV acquisition as demonstrated in Indonesia, where HIV prevalence far exceeds that in male sex workers $(22 \%$ $v 3.6 \%$ ) [see page 536]..$^{20}$ Many transgender people working in Europe are immigrants from countries with significant HIV prevalence rates and may be working illegally [see page 541]. ${ }^{21}$ This makes it very difficult for national surveillance systems to monitor HIV prevalence trends among this high risk and vulnerable population.

In conclusion, the improvement of men's sexual health continues to provide a challenge to clinicians, scientists, and politicians alike. Behavioural interventions and health promotion campaigns need to be targeted at high risk populations and the behaviours underlying the worsening trends in male sexual health.

Sex Transm Infect 2004;80:423-424. doi: $10.1136 /$ sti.2004.013540

Correspondence to: $\operatorname{Dr}$ D A Lewis, Head of STI Reference Centre, National Institute of Communicable Diseases, Private Bag X4, Sandringham 2131, South Africa; david.lewis@nhls.ac.za

\section{REFERENCES}

1 Tyler M. Addressing the need: developing practice with young black men to enable them to access health services. Working with young men 2002; 1:22-26.

2 Hancock J. Can mainstream services learn from male only sexual health pilot projects? Sex Transm Inf 2004:80:484-7.

3 MacDonald ND, Dougan S, McGarrigle C, et al. Recent trends in diagnoses of HIV and other sexually transmitted infections in England and Wales amongst men who have sex with men. Sex Transm Inf 2004;80:492-7.

4 Dodds J, Mercey D. Sexual health survey of gay men-London 2002: summary of results. London: Royal Free and University College Medical School, September 2003.

5 Smith AMA, Grierson J, Wain D, et al. Associations between the sexual behaviour of men who have sex with men and the structure and composition of their social networks. Sex Transm Inf 2004;80:455-8.

6 Elford J, Bolding G, Davis $M$, et al. Trends in sexual behaviour among London gay men 1998-2003: implications for HIV prevention and sexual health promotion. Sex Transm Inf 2004;80:451-4.

7 Hickson FCl, Reid D, Weatherburn P, et al. HIV, sexual risk and ethnicity among men in England who have sex with men. Sex Transm Inf 2004;80:443-50.

8 Lau JTF, Kim JH, Lau M, et al. HIV-related behaviours and attitudes among Chinese men who have sex with men in Hong Kong: a population-based study. Sex Transm Inf 2004:80:459-65.

9 Cox J, Beauchemin J, Allard R. HIV status of sexual partners is more important than antiretroviral treatment-related perceptions for risk taking by HIV-positive MSM in Montreal, Canada. Sex Transm Inf 2004;80:518-23.

10 Gorbach P, Galea JT, Amani B, et al. Don't ask, don't tell: patterns of HIV disclosure among HIV positive men who have sex with men (MSM) with recent STI practicing high risk behaviour in Los Angeles and Seattle. Sex Transm Inf 2004;80:512-17.

11 Health Protection Agency. HIV and other sexually transmitted infections in the United Kingdom in 2002. Annual Report, November 2003

12 Department of Health. The National Strategy for Sexual Health and HIV. London: Department of Health, July 2000.

13 Armitage CM, Curran B, Wright S, et al. Are we getting the message across? Trends among young men attending a young people's clinic. Sex Transm Inf 2004:80:477-9.

14 Lewis DA, McDonald A, Thompson G, et al. The 374 clinic: an outreach sexual health clinic for young men. Sex Transm Inf 2004:80:480-3.

15 Crosby RA, Salazar LF, DiClemente RJ. Lack of recent condom use among detained adolescent males: a multi-level investigation. Sex Transm Inf 2004;80:425-9.

16 Ferguson A, Pere M, Morris C, et al. Sexual patterning and condom use among a group of HIV-vulnerable men in Thika, Kenya. Sex Transm Inf 2004;80:435-9

17 Thomsen S, Stalker M, Toroitich-Ruto C. Fiffy ways to leave your rubber: how men in Mombasa rationalise unsafe sex. Sex Transm Inf 2004;80:430-4.

18 Haley N, Roy E, Leclerc P, et al. HIV risk profile of male street youth involved in survival sex. Sex Transm Inf 2004:80:526-30.

19 Kuyper LM, Lampinen TM, Li K, et al. Factors associated with sex-trade involvement among male participants in a prospective study of injection drug users. Sex Transm Inf 2004;80:531-5

20 Pisani E, Girault P, Gultom M, et al. HIV, syphilis infection and sexual practices among transgenders, male sex workers and other men who have sex with men in Jakarta, Indonesia. Sex Transm Inf 2004;80:536-40.

21 Zaccarelli M, Spizzichino L, Venezia S, et al. Changes in regular condom use among immigrant transsexuals attending a counselling and testing reference site in central Rome: a 12 year study. Sex Transm Inf 2004;80:541-5. 